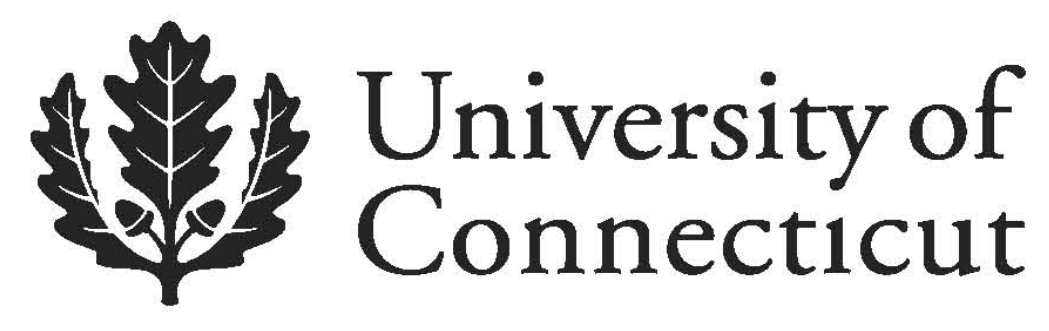

Department of Economics Working Paper Series

\title{
An experiment on strategic capacity reduction
}

\section{Mikhael Shor}

University of Connecticut

Working Paper 2012-23

July 2008

365 Fairfield Way, Unit 1063

Storrs, CT 06269-1063

Phone: (860) 486-3022

Fax: (860) 486-4463

http://www.econ.uconn.edu/

This working paper is indexed on RePEc, http://repec.org 


\title{
An experiment on strategic capacity reduction ${ }^{\dagger}$
}

\author{
Mikhael Shor \\ Owen Graduate School of Management, Vanderbilt University
}

Revised July 2008

\begin{abstract}
A firm may strategically decrease capacity to gain bargaining power over its suppliers. Equilibrium models of competition imply that the incentive to reduce capacity to gain buyer power is small because the buyer captures all available surplus by excluding even a single supplier. However, these models can rest on behaviorally untenable actions prescribed to suppliers in equilibrium. In this paper, we test this theory using a laboratory experiment in which subjects compete to supply a single firm. We find that as capacity decreases, so do suppliers' price requests, but according to a pattern quite different from equilibrium predictions. We find that a buyer has incentive to exclude at least $30 \%$ of available suppliers. This result calls for greater antitrust oversight and offers a behavioral explanation for observed reductions in capacity.
\end{abstract}

JEL Classification: C78, C90, L13

Keywords: Strategic capacity reduction, Bargaining power, Ultimatum games, Behavioral economics

\footnotetext{
${ }^{\dagger}$ I would like to thank Martin Dufwenberg, Luke Froeb, Ron Harstad, Kai-Uwe Kühn, Hans-Theo Normann, JeanLouis Rullière, Bart Victor, Rami Zwick, and participants at the North American Regional Meeting of the Economic Science Association for helpful comments and suggestions.
} 


\section{Introduction}

Health insurers often restrict the number of drugs of a certain class on their formularies. Airports may artificially limit the availability of gates or runways. Pharmaceutical benefit managers restrict the number of drug stores in their retail networks. Grocery stores often limit available shelf space for competing products. Forcing suppliers to compete over limited capacity may allow insurers to extract more favorable prices from pharmaceutical companies (e.g., Huskamp, et. al., 2005), airports to encourage competition for slotting allowances among airlines (e.g., Fan and Odoni, 2002), benefit managers to gain better prices for retail pharmaceutical services, and grocery stores to extract side payments from the brands that they do carry: "By limiting its shelf space, a retailer can force manufacturers to compete more vigorously for its patronage, which then allows it to extract from them better terms of trade" (Marx and Shaffer, 2004, p. 2). Reducing capacity lowers the total value of the firm's offerings to consumers but may increase the bargaining power of the firm with respect to its suppliers.

Antitrust examination of slotting allowances has focused almost exclusively on supplier market power. ${ }^{1}$ The notion that buyers can gain better prices by limiting supply has not gained a lot of traction with economists. First, there are obvious pro-competitive explanations for capacity reduction that have little to do with buyer power. For example, Klein and Wright (2007) explain limited shelf space and slotting allowances as a way of aligning a retailer's incentives with those of manufacturers while Sullivan (1997) offers evidence that they decrease consumer search costs, raising welfare. Second, under traditional bargaining models, a firm's incentive to reduce capacity in equilibrium is minimal. However, these theoretical foundations for buyer power depend on behavioral assumptions that may be untenable.

Consider 20 competing suppliers who submit simultaneous take-it-or-leave-it bids to a single producer. If each supplier is equally valuable, equilibrium predictions (detailed in the next section) are stark: suppliers capture the entire available surplus when capacity is sufficient to include all suppliers, and will bid away all surplus when capacity constraints bind. Therefore, the producer faces little incentive to decrease capacity since excluding even a single supplier allows it to extract all surplus. However, this equilibrium is supported only in weakly dominated

\footnotetext{
${ }^{1}$ The most common concern is that slotting allowances can allow one manufacturer, through high payments, to exclude his rivals. See, for example, the testimonies of FTC Chairman Pitofsky (2000) and FTC Competition Bureau Deputy Director Tom (1999). Little consideration is given to the power exercised by the buyer, despite evidence that most fees of this type are initiated by buyers and often opposed by suppliers (Arquit, 1991).
} 
strategies, requiring suppliers to request a payment of zero whenever capacity constraints bind, ensuring themselves a profit of zero regardless of the behavior of competitors. While all suppliers expect to earn zero in equilibrium, it seems a troubling assumption that they will play the only strategy that guarantees them zero profits.

Economics experiments have lent insights into antitrust issues where the theory has proved equivocal or rested on behaviorally untenable axioms (see Normann, 2006, for a review). Recently, enforcement agencies have begun to commission economics experiments related to pending antitrust issues. For example, in 2002, the FCC released an experimental working paper as part of its review of several cable and telecommunications acts (Bykowsky, Kwasnica, and Sharkey, 2002) and sought public comment from other experimental economists (e.g., Schotter 2002). Similarly, the FTC has relied on experimental evidence (e.g., Deck and Wilson, 2007).

In this paper, we test the behavioral assumption with an experiment in which subjects act as competing suppliers under varying capacity conditions. We find that experimental subjects capture a greater share of the surplus than predicted theoretically, and that their bids vary with available capacity. The pattern of these bids suggests that buyers have incentive to commit to a capacity that excludes at least $30 \%$ of available suppliers. This reflects a significant efficiency loss as a result of a monopolist's strategic capacity decision ${ }^{2}$ and offers an alternate explanation for the ability of buyers to gain bargaining power by reducing capacity.

We reach three conclusions in this manuscript. First, both Nash and quantal response equilibria (McKelvey and Palfrey, 1995) generally fail to predict subjects' play. Second, notions of fairness in concert with strategic concerns explain observed data. Lastly, firms have significant incentives to reduce capacity far below efficient levels.

\section{Experimental Design and Theoretical Predictions}

Subjects participated in a laboratory market and assumed the role of suppliers vying for a limited number of positions with a capacity-constrained monopsonist. Each of $N=20$ identical suppliers can provide additional revenue of $V$ for the firm. Each market was characterized by a capacity

\footnotetext{
${ }^{2}$ In other contexts, models of strategic capacity constraints include Spence (1977) and Bulow, Geanakoplos, and Klemperer (1985) who find that incumbents may increase capacity to deter entry, and Gelman and Salop (1983) who show an entrant may have incentive to reduce capacity. Excess capacity can also serve as a commitment to suppliers to avoid opportunistic behavior (von Ungern-Sternberg, 1988).
} 
level, $k$, which serves as an upper limit on the total number of accepted suppliers. Treatments reflected capacities between 4 and 20 in increments of two, for a total of nine different capacity possibilities. Sixty subjects each bid in three different, randomly chosen, capacity conditions for a total of 180 bids (20 at each level of capacity). ${ }^{3}$

The experimental design shares similarities with past experiments on multi-party ultimatum and market games. Roth, Prasnikar, Okuno-Fujiwara, and Zamir (1991) and Prasnikar and Roth (1992) have nine proposers (suppliers in our context) submitting simultaneous offers with at most one being accepted. Dufwenberg and Gneezy (2000) and Dufwenberg, Gneezy and Rustichini (2005), in a similar framework, have between two and four competitors for a single prize. Abbink et. al. (2003) considers three proposers offering sequentially with the game ending as soon as one offer is accepted. While these past experiments allow at most one offer to be accepted, the present experiment varies the number of offers that will be accepted, allowing for a measure of the profit effects of reduced capacity.

Each supplier contributed $\$ 10$ (\$10 million in experimental dollars) to the monopsonist's profit. Each supplier simultaneously proposed a price $p$ that she would receive if her offer was accepted. The $k$ lowest offers were accepted (as long as they were not greater than \$10) and those subjects were paid their asking prices. Suppliers whose offers were not accepted earned zero, with ties broken randomly. Appendix A details the scenario posed to subjects. A subject could earn up to $\$ 30$ (\$10 in each market) if the maximum offer was accepted in each market. The average subject earned \$10.64 in addition to a $\$ 5$ participation fee. Experimental subjects required an average of 20 minutes to complete the experiment. Additional experiments, one involving corporate executives as subjects, and another allowing for repeated play, are described later.

The resulting game among the twenty subjects in each treatment has a stark equilibrium prediction. Effectively, the game is a discriminatory auction in which the $k$ lowest bidders received a payment equal to their bids. If capacity is $k=20$, and thus enough capacity exists to accommodate all suppliers, each requests to keep the entire $\$ 10$. If capacity is $k<20$, even a

\footnotetext{
${ }^{3}$ The three capacity conditions in which a subject bid were randomly selected subject to the constraint that all three conditions are at least 4 apart from each other. A subject could bid in the treatments $k=\{6,10,20\}$ but not in $k=\{6,10,12\}$ since 10 and 12 are adjacent treatments. This maintains independence of observations in pair-wise statistical tests of adjacent treatments.
} 
singular reduction in capacity to 19 ensures that the firm appropriates all profits. ${ }^{4} \mathrm{~A}$ continuum of equilibria exists but each results in suppliers forfeiting the entire available surplus, $10 \mathrm{k}$ to the monopsonist. Specifically, in all equilibria, $k+1$ subjects request 0 , with remaining subjects free to request any amount. This equilibrium result is a simple extension of the argument in Roth, Prasnikar, Okuna-Fujiwara, and Zamir (1991) to the case of $k>1$. All suppliers earn zero profits. No alternate strategy can result in a positive payoff since any request above zero is rejected when others play their equilibrium strategies. Thus, the theoretical benchmark would be profits of $\$ 10$ for each subject in the treatment with $k=20$ and profits of $\$ 0$ in all treatments with $k<20$. While any single treatment with $k<20$ would offer a test of the equilibrium predictions, treatments were run at varying levels of $k$ both to determine how subject behavior changes with the extent of the capacity constraint, and to deduce the resulting incentives for a firm to reduce capacity.

The equilibrium of this game is somewhat unsatisfactory from a behavioral perspective. First, the equilibrium in capacity-constrained conditions requires the playing of weakly dominated strategies by requesting a payment of zero for inclusion. Even if subjects are purely profit maximizing, one may reason: if I request zero, no profile of competitors' bids can lead to a positive payoff for me, but if there is any chance that others will also ask for positive amounts (perhaps derived from misreading of the game, a sense of fairness, or thinking similar to mine) a positive request by me provides some chance of positive profit (Dufwenberg, Gneezy, Goeree, and Nagel, 2007). A discrete version of the game could allow positive equilibrium profits, but no higher than a fraction of the lowest possible bid. Second, the preponderance of evidence drawn from two-player ultimatum games suggests that subjects deviate sharply from purely profitmaximizing behavior (see Güth and Tietz 1990; Roth 1995 and references therein). A near-even split of the pie generally results, though whether this is due to a sense of fairness or to strategic considerations is subject to debate. ${ }^{5}$ Since only some suppliers' bids will be accepted and others will earn no revenue, it perhaps violates fairness norms for me to expect a large share of industry profits. A secondary concern comes from the fact that one's position is somewhat precarious. While I might have a notion of what my fair profits ought to be, I also note that others are gunning for my position as a supplier. To keep my position secure, I may need to sacrifice some of my profits. Thus, both equity and strategic competition concerns may come in to play.

\footnotetext{
${ }^{4}$ Here, relative bargaining power between producers and suppliers is determined solely by available capacity. In different contexts, authors have altered bargaining power by having capacity constraints never bind while altering the curvature of the surplus function (e.g., Normann, Ruffle, and Snyder, 20077; Froeb and Shor, 2008).

${ }^{5}$ For example, see Kahneman, Knetsch, and Thaler (1986), Thaler (1988), Ochs and Roth (1989), Weg and Zwick (1994), Fehr and Schmidt (1999), Zamir (2001), and Nagel (2001).
} 
To examine the motivation for subjects' bids, an equity and a competition benchmark are composed using surveys of a different population than experimental subjects. In a setting similar to the experiment, survey respondents provide their measures of a "fair" request by a supplier and, in a different survey, of a measure of a share of profits sufficient to maintain a supplier's competitive position. Survey results match the observed bidding data in the experiment. However, these results are obtained using MBA students as subjects. Since notions of equity found in the laboratory among student-subjects do not necessarily extend to the operation of companies, additional experimental sessions were run with middle to upper level executives of manufacturing companies involved in both upstream and downstream supply chains. These sessions provide very similar conclusions. Similarly, repeating the experiment for twenty rounds, allowing for subject learning, does not change the qualitative findings.

\section{Experimental Results}

Observed bids at each capacity level are presented in Figure 1. In the absence of capacity constraints, with 20 subjects competing for exactly 20 slots, participants generally demanded nearly their full value from the firm. In the capacity-constrained conditions, bids failed to conform to equilibrium predictions. ${ }^{6}$ Not a single subject requested a payment of zero, and amounts very close to zero were observed only when capacity was severely limited to four or six offers. Average bids increase with capacity. Since lower capacities also imply that fewer bids are accepted, the change in accepted bids across treatments is more pronounced (Table 1). ${ }^{7}$ For example, when capacity is 18 , all bids below 9 are accepted with an average winning bid of 7.72. At a capacity of 6 , only bids less than 1 are accepted. Thus, the firm keeps less than $25 \%$ of the total generated surplus when capacity is 18 but almost the entire surplus at a capacity of 6 , making a capacity of 6 a more profitable capacity level.

At first glance, there is substantial incentive to decrease capacity in order to gain bargaining power. A capacity of 12 is most profitable and corresponds to a $40 \%$ decrease in capacity, substantially above theoretical predictions. Since we observe twenty bids at each capacity level, a single estimate of profit is obtained. Bootstrap methods provide a robustness check and a

\footnotetext{
${ }^{6} \mathrm{p}<.001$ in all treatments both for direct t-tests and using bootstrap standard errors (1000 repetitions). KolmogorovSmirnov tests cannot reject that bids in each of these treatments are normally distributed (p-values .11 to .99). ${ }^{7}$ Mann-Whitney test finds that average accepted bids increase significantly from $k=6$ to 8 ( $\left.\mathrm{p}=.003\right), 8$ to 10 (.044), 12 to $14(.028), 14$ to $16(<.001), 16$ to $18(<.001)$, and 18 to $20(<.001)$. Increases from 4 to 6 and from 10 to 12 are not significant at $5 \%$.
} 


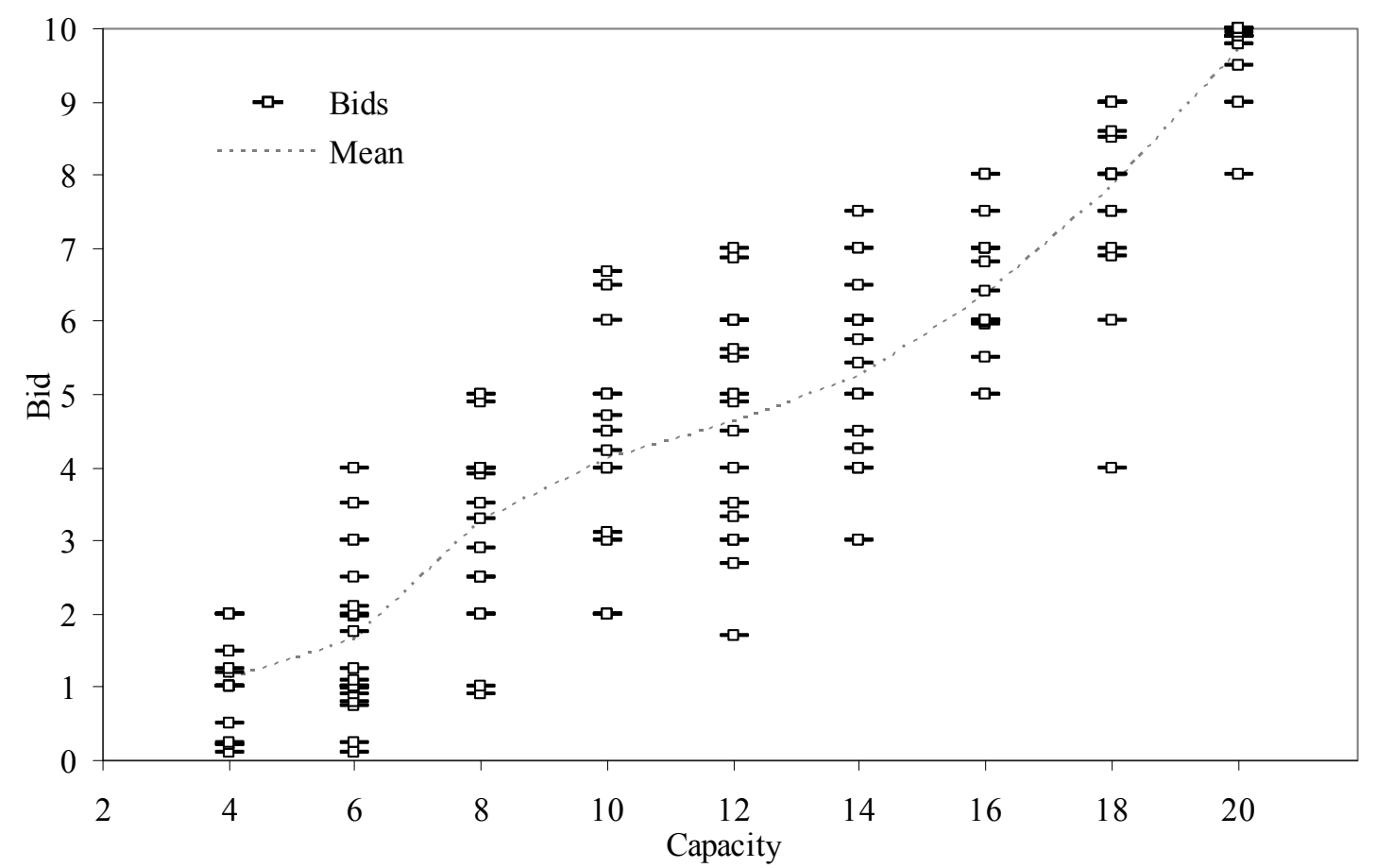

Figure 1. Raw Data: Bids at varying levels of capacity.

Table 1. Experimental results

\begin{tabular}{c|ccc|cc}
\hline \hline & & \multicolumn{2}{c|}{ Bids } & & \multicolumn{2}{c}{ Firm Profit } \\
\cline { 3 - 5 } Capacity & Average & $\begin{array}{c}\text { Maximum } \\
\text { Accepted }\end{array}$ & $\begin{array}{c}\text { Average } \\
\text { Accepted }\end{array}$ & Experiment & $\begin{array}{c}\text { Equilibrium } \\
\text { Prediction }\end{array}$ \\
\hline 4 & 1.11 & 0.25 & 0.19 & 39.3 & 40 \\
6 & 1.65 & 0.99 & 0.63 & 56.2 & 60 \\
8 & 3.27 & 2.90 & 1.98 & 64.2 & 80 \\
10 & 4.11 & 4.23 & 2.93 & 70.7 & 100 \\
12 & 4.63 & 5.00 & 3.64 & 76.4 & 120 \\
14 & 5.25 & 6.00 & 4.64 & 75.1 & 140 \\
16 & 6.36 & 7.00 & 6.04 & 63.4 & 160 \\
18 & 7.85 & 9.00 & 7.72 & 41.0 & 180 \\
20 & 9.72 & 10.00 & 9.72 & 5.7 & 0 \\
\hline \hline
\end{tabular}

measure of standard deviation. Ten thousand auctions are simulated at each capacity level, drawing 20 bids from the empirical distribution, with replacement (Figure 2). Additionally, 10,000 bootstrap samples of the difference in profits is estimated for each pair of capacity levels. Reducing capacity from 20 to 18 , from 18 to 16 , and from 16 to 14 offer highly significant profit improvements $(\mathrm{p} \leq 0.01)$. Profits at capacities of 10,12 , and 14 are indistinguishable at any reasonable level of significance. Nevertheless, we can infer that incentives exist to decrease capacity at least $30 \%$ below the efficient level to a capacity of 14 . 


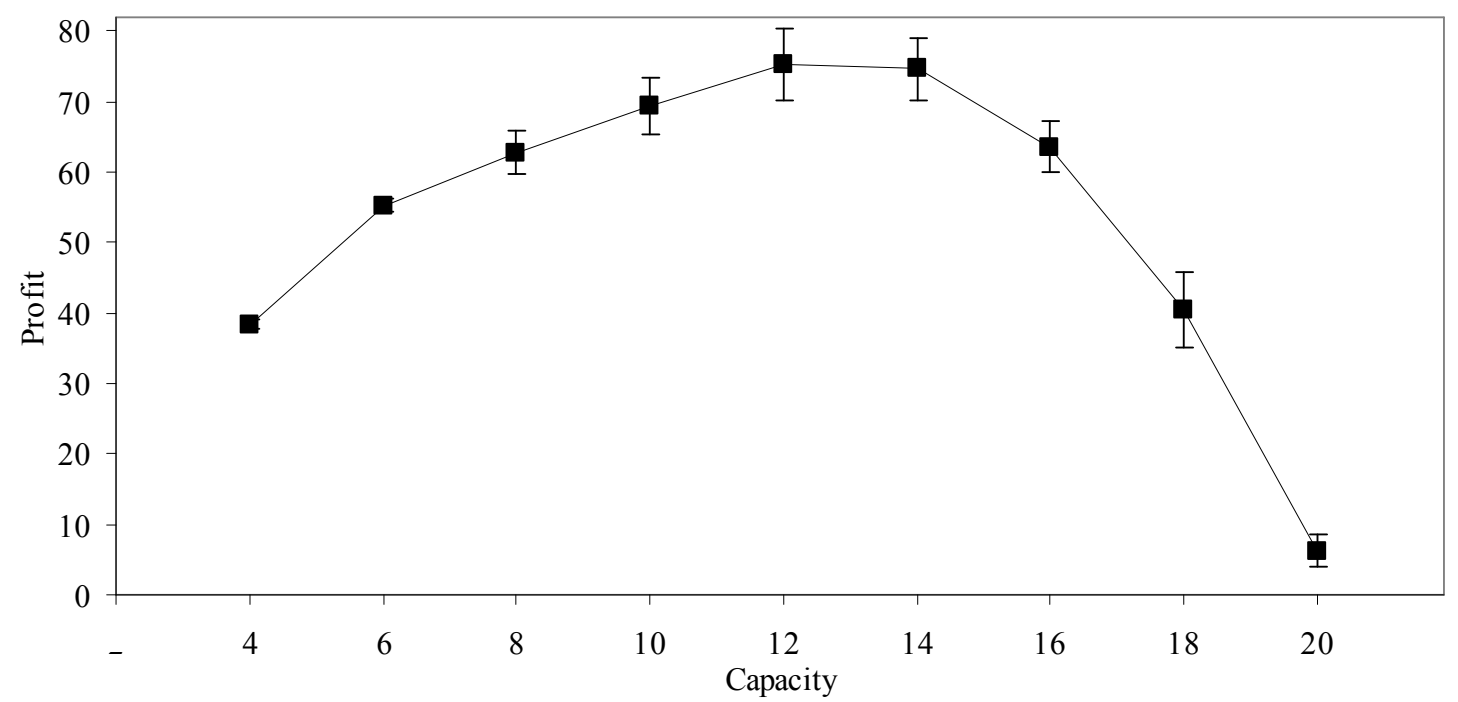

Figure 2. Bootstrap estimates of firm profit at varying capacity levels. Error bars represent one standard deviation.

Theoretical predictions about play in this game serve neither a positive nor a normative role. First, subjects do not conform to equilibrium play. Second, each accepted bid resulted in positive payoffs, exceeding equilibrium payoffs of zero. Educating subjects about equilibrium play is unlikely to improve their payoffs, as it might, for example, in experiments on the winner's curse.

Subsequent sections of this manuscript attempt to explain subjects' behavior, and examine its robustness both to subject pool and to repeated play. The first explanation maintains equilibriumlike thinking while relaxing strict rationality, in the form of a quantal response equilibrium. The second approach considers whether subjects use more myopic heuristics rather than optimally replying to predicted behavior, perhaps in the form of social norms. In particular, I examine whether equity concerns play a role.

\section{Quantal Response}

The quantal response equilibrium (QRE, McKelvey and Palfrey, 1995) allows for departures from equilibrium and heterogeneity in subjects' play by replacing the equilibrium rationality assumption with a stochastic choice model. While several derivations of the QRE are possible, one may imagine that a player's utility additively incorporates a mean-zero random variable, either due to mistakes or unobserved idiosyncrasies in preferences. An experiment specifies $\pi_{i}\left(s_{i} \mid s_{-i}\right)$ as player $i$ 's payoffs from $s_{i}$ when others play $s_{-i}$, but realized utilities are given by 


$$
\hat{\pi}_{i}\left(s_{i} \mid \sigma_{-i}\right)=\pi_{i}\left(s_{i} \mid \sigma_{-i}\right)+\varepsilon_{i}\left(s_{i}\right)
$$

where $\varepsilon_{i}\left(s_{i}\right)$ is a mean-zero random variable and $\sigma_{-i}$ is the vector of opponents' mixed strategies. If players maximize realized utility, then the probability a strategy is played is equal to the probability that it yields the highest realized payoff, given the distribution of $\varepsilon_{i}\left(s_{i}\right)$. The resulting probability distribution over strategies, or quantal response function, generalizes best responses. As “errors" (or realizations of $\varepsilon$ ) become arbitrarily small, QRE converges to a Nash equilibrium.

Haile, Hortacsu, and Kosenok (2007) show that arbitrary error structures may provide a fit of any generated data, though Goeree, Holt, and Palfrey (2005) note that suitable restrictions do limit the data that can be explained by a QRE. In particular, we adopt the logistic quantal response equilibrium, in which all error terms are identical extreme value distributions. This implies that the probability of playing strategy $s_{i}$ is given by:

$$
\sigma_{i}\left(s_{i} \mid \sigma_{-i}\right)=e^{\lambda \pi\left(s_{i} \mid \sigma_{-i}\right)} / \Sigma_{t} e^{\lambda \pi\left(t \mid \sigma_{-i}\right)}
$$

The quantal response equilibrium is a fixed point of the vector $\sigma$ much like a Nash equilibrium is a fixed point in best responses. When $\lambda=0$, disturbances are so large that all strategies are played with equal probability. In the limit, as $\lambda \rightarrow \infty$, all probability is assigned to the strategy with the highest payoff, and QRE converges to Nash.

The single parameter $\lambda$ is estimated using maximum likelihood. First, the set of strategies is made discrete by mapping all observed strategies to the nearest element of a 101-strategy grid at 0.1 intervals. Then, for each value of $\lambda$, nine equilibria are calculated numerically, one for each capacity condition. The value of $\lambda$ which maximizes the product of the probabilities of observed actions is found to be 0.264 . The resulting distributions are presented in Figure 3.

Qualitatively, the QRE resembles the data, as its peaks correspond to subject play. However, quantitatively, the QRE places nearly uniform probability on each strategy, with the peaks in the figure representing only minor departures from a nearly-flat probability density function. When capacity is 4, even though the QRE exhibits a peak at a strategy of 1.3 (near the 1.1 average for subjects), the expected strategy given by the QRE distribution is 4.84, only slightly below the expected value of a uniform distribution on $[0,10]$. When capacity rises to 18 , the distribution attains its peak at 7.5 (for subjects, it is 7.9), but the distribution's expectation is only 5.61 . 

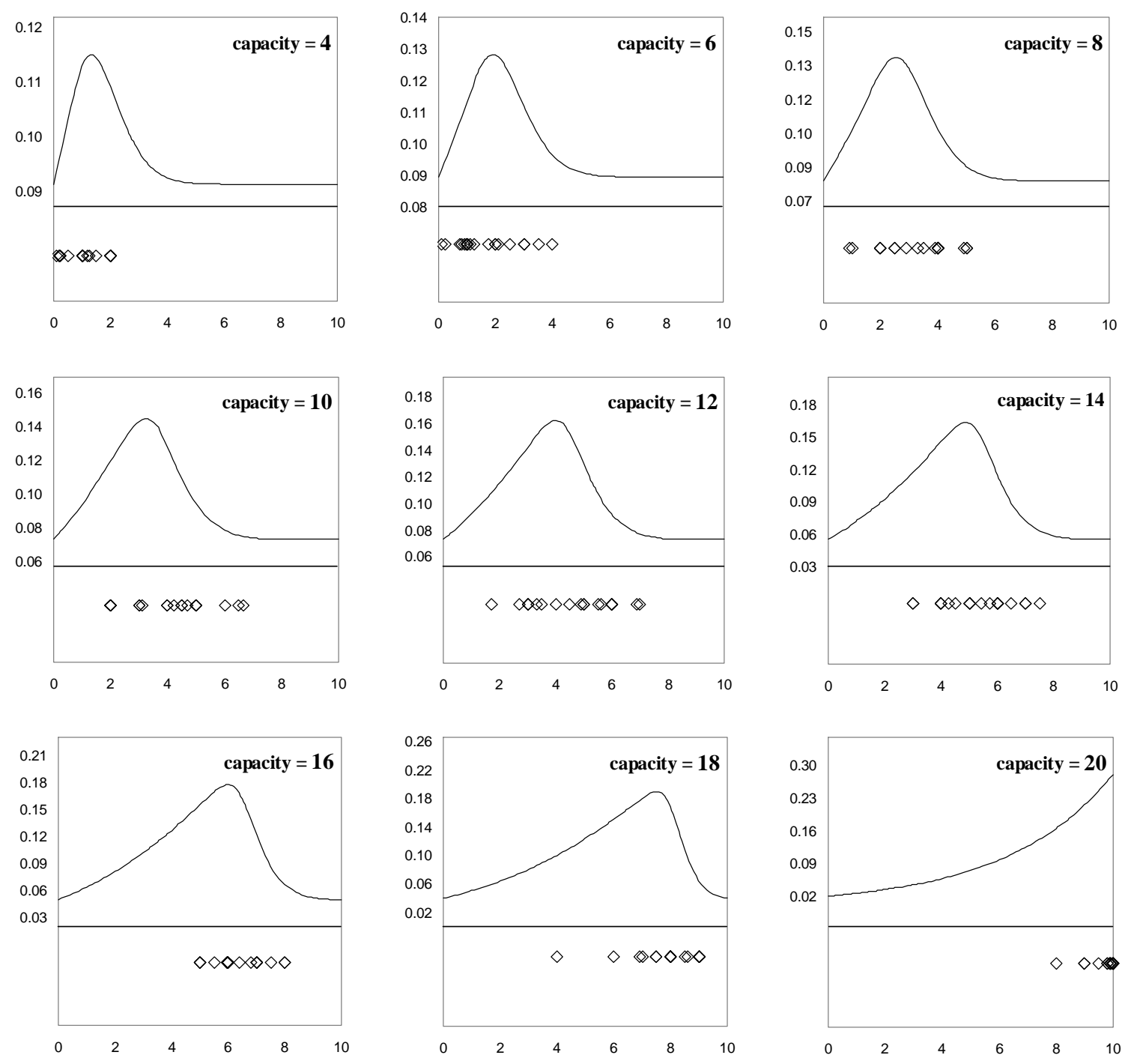

Figure 3. Quantal response equilibrium predictions. The QRE distribution is in the upper portion of each panel. Actual subject decisions (represented by diamonds) are in the lower portion.

When capacity is 16 , subjects' strategies all fall in the interval between 5 and 8 , representing $30 \%$ of the strategy space. The QRE assigns $42 \%$ of the probability to this interval which predicts that subjects, more often than not (58\% of the time), will play a strategy outside this interval. To understand why the QRE performs poorly, we can look more closely at how the QRE is determined. Denote by $p$ the probability that a bid of 5 is accepted, given the behavior of other players, when capacity is 16 . Since the probability that a bid of 4 is accepted must be at least as large as $p$, the weight placed on the strategy 4 relative to the strategy 5 is at least $\mathrm{e}^{4 \lambda p} / \mathrm{e}^{5 \lambda p}$ $=\mathrm{e}^{-\lambda p}$. For the QRE to provide an accurate description of the data, which requires placing little 
weight on the strategy $4, \lambda$ must be sufficiently large. However, large values of $\lambda$ lead the QRE to converge to the Nash equilibrium of zero, making neither 4 nor 5 likely. Maximizing likelihood trades off between sufficiently high values of $\lambda$ to avoid predictions of uniform play and low values to provide a QRE distant from Nash, matching the data. The latter effect dominates and the value of $\lambda$ that maximizes likelihood leads to predictions of nearly uniform play.

If subjects do not conform to equilibrium play, what heuristic explanations of behavior may be offered? In Section VI, a simple equity notion tempered by strategic concerns is considered. Any conclusions about heuristic play among student subjects must necessarily confront the possibility that "real world" subjects may act differently. To address this, the next section presents data on a similar experiment with a subject pool comprised of top executives at companies involved in supply chain bidding. Their behavior is not markedly different from the pool of student subjects.

\section{Executives as Subjects}

Upper level managers and executives at two major (multibillion dollar revenue) manufacturing companies also took part in the experiment. One company manufactures specialty chemicals and the other is a supplier for the automotive industry. Executives of both companies face supply chain decisions both upstream and downstream - procuring raw materials and selling finished goods to other manufacturers. Sessions were held during two-day executive training courses.

Several differences exist between these sessions and those with MBA subjects. First, all subjects competed against all others in the same session. Rather than having twenty suppliers vie for inclusion, the number of suppliers was equal to the number of attendees. Second, subjects received no payment for their participation. Instead, subjects were aware that "selected results" (with subject names) would be presented to the group. These sessions differ from those with MBA student subjects in subjects' business experience, remuneration, and number of participants vying for slots. Nevertheless, we observe quite similar results. Since capacities, $k$, and number of subjects vying for those slots, $N$, in these treatments differs from those with MBA subjects, we examine subject behavior as a function of $k / N$, the proportion of competitors whose offers are accepted (Table 2). In essence, we hypothesize that 20 subjects competing for ten slots (one of the treatments with MBA subjects) is similar to 40 subjects competing for 20 slots (one of the executive subject treatments) since, in both cases, half of all bids are accepted. 
Table 2. Experimental treatments with executives as subjects

\begin{tabular}{lcccc}
\hline \hline & & $\begin{array}{c}\text { Number of } \\
\text { subjects }(\boldsymbol{N})\end{array}$ & $\begin{array}{c}\text { Capacity } \\
(\boldsymbol{k})\end{array}$ & $\boldsymbol{k} / \boldsymbol{N}$ \\
\hline \multirow{2}{*}{ Session 1 (Firm 1) } & Treatment 1 & 40 & 8 & 0.20 \\
& Treatment 2 & 40 & 20 & 0.50 \\
& Treatment 3 & 40 & 32 & 0.80 \\
Session 2 (Firm 1) & Treatment 1 & 52 & 20 & 0.38 \\
& Treatment 2 & 52 & 30 & 0.58 \\
& Treatment 3 & 52 & 52 & 1.00 \\
Session 3 (Firm 2) & Treatment 1 & 32 & 10 & 0.31 \\
& Treatment 2 & 32 & 21 & 0.63 \\
& Treatment 3 & 32 & 30 & 0.94 \\
Session 4 (Firm 2) & Treatment 1 & 47 & 25 & 0.53 \\
& Treatment 2 & 47 & 40 & 0.85 \\
& Treatment 3 & 47 & 47 & 1.00 \\
\hline \hline
\end{tabular}

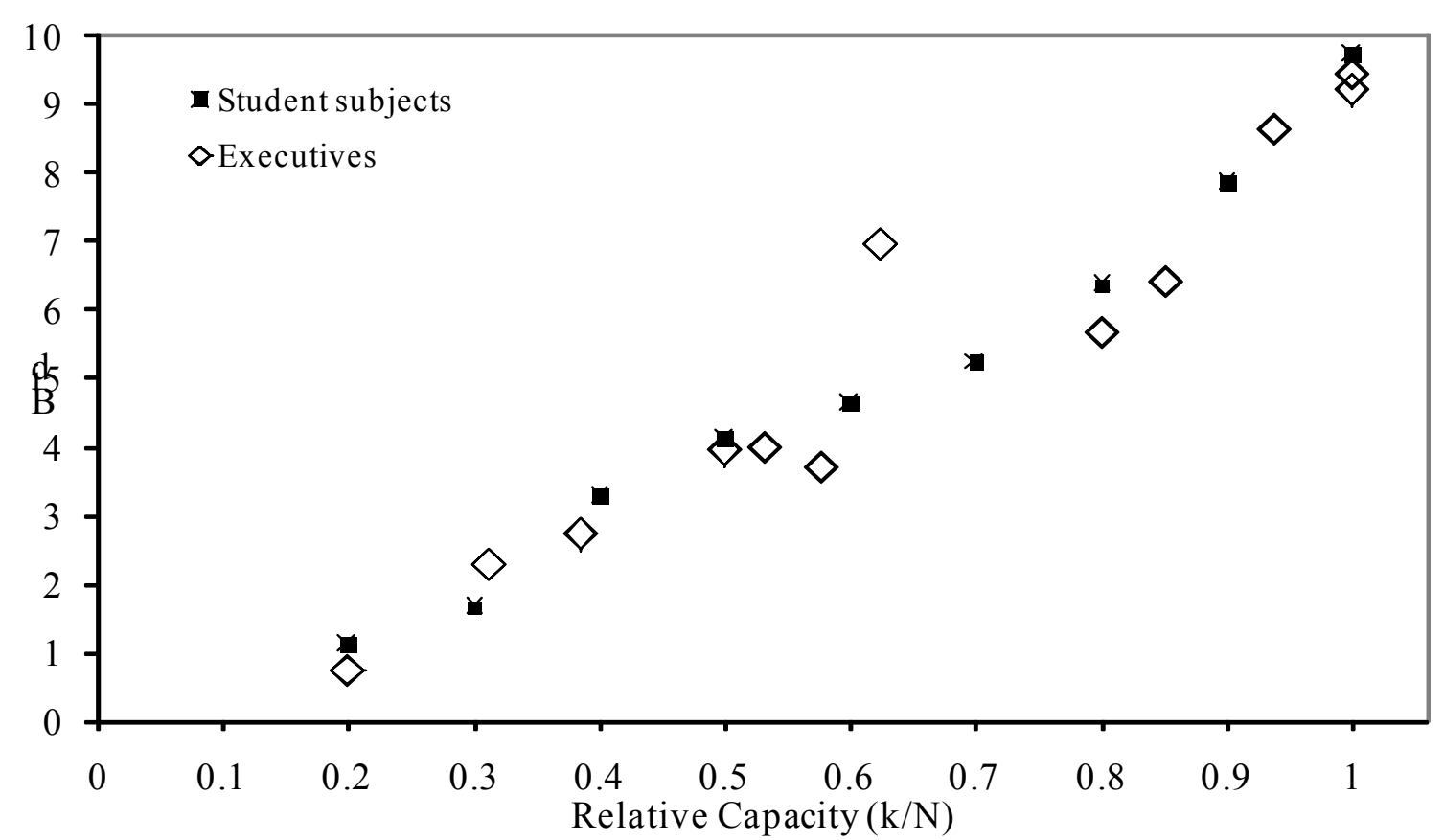

Figure 4. Average strategy by capacity constraint for student and executive subject pools. 
Figure 4 represents average bids for each subject pool. With the possible exception of one session, the bids appear quite similar. Bids may also be regressed on $k / N$ for each subject pool. Neither intercepts nor slopes differ significantly across subject populations ( $\mathrm{p}=0.70$ and 0.86 ). ${ }^{8}$ This result offers tentative support for invariance of the conclusions to subject pool and for the dependence of bids only on the ratio of the capacity to number of competing suppliers, $k / N$.

What can explain subjects' deviation from equilibrium predictions? One executive stated that "this game is simplistic but still similar to what we face every day. In our business, we compete against other suppliers in what is, essentially, a commodity business. Our only differentiation is price." When asked how this participant selected bids in the experiment, the participant replied, "well, the idea is to treat everyone fairly, while still securing a sufficient profit for ourselves," though offered no specific formulation for these concepts. While admittedly anecdotal, this sentiment does suggest that "selfish" strategic concerns and fairness norms may both play a role. The next section develops these ideas.

\section{Behavioral Surveys}

In the voluminous research into ultimatum games, subjects systematically diverge from profitmaximizing behavior. An equitable division of surplus often serves as a focal point which some players may temper with strategic consideration of how far they can deviate from this norm to increase personal profit. For example, a player might "recognize that a fifty-fifty split is 'fair,' but would seek to take more" (Roth, Prasnikar, Okuna-Fujiwara, and Zamir 1991, p. 1091). ${ }^{9}$ In this experiment, similar fairness and strategic concerns may arise. Since the monopsonist is not a human subject, equity issues only arise across competitors. What is "fair" in the present context is less obvious than in ultimatum games since some subjects will, by design, earn nothing. Two surveys provide a measure of what constitutes a fair allocation in this context and what strategic concerns temper this in light of competition. Survey results are compared to experimental data.

\footnotetext{
${ }^{8}$ We observe 3 bids per subject, raising issues with regression analysis. Bootstrap (5,000 repetitions) estimates, stratified by subject so that one bid per subject is randomly drawn, produce similar results.

${ }^{9}$ Many ultimatum experiments have examined the balance between fairness and strategic concerns, including Güth and van Damme (1998) and Forsythe, Horowitz, Savin, and Sefton (1994) who find that offers to powerless players are generally positive though lower than offers to players who can reject the offer. Shor (2007) argues that this may be due to procedural justice concerns rather than strategic ones. Walster, Walster, and Berscheid (1978) were first to note that selfish proposers may wish to seem fair as a strategic tactic (echoed by, e.g., Camerer and Thaler, 1995).
} 
Survey Instrument. In the first survey, respondents read a scenario which paralleled the experiment and were asked what constitutes a "fair" profit for a supplier when the buying firm has some capacity constraint. A second survey measured competitive concerns, asking respondents what percentage of their profits they would need to share with the buying firm to ensure their future position among its suppliers. ${ }^{10}$ Each survey varied the capacity levels from among the set $\{4,8,12,16,20\}$. A total of 100 respondents participated in Survey 1 (20 per capacity level) and 50 participated in survey 2 (10 per capacity level). The survey instruments are in Appendix B. Respondents were drawn from the same subject population as experimental subjects (MBA students at the author's institution) but no subject participated in both a survey and the experiment, to avoid confounding of either. The following hypotheses are examined:

H1: Appraisals of "fair profit" will be proportional to available capacity; fair profit $=(k / N) V$.

H2: Subject appraisal of the percentage of profit they can keep while remaining one of the selected companies will increase with capacity, though no functional form is hypothesized.

The first hypothesis is at odds with findings on the total sacrifice effect in which subjects seem to keep for themselves the same amount regardless of the number of people with whom it is shared (Bolton, Katok and Zwick 1998; Selten and Ockenfels 1998).

Survey Results. In determining a "fair profit," respondents appear to compare their payoffs to what each should equitably receive even though capacity limits mandate that many subjects will actually receive no payment. At each capacity level, the modal answer corresponded to the fairness prediction of Hypothesis $1(\mathrm{kV} / \mathrm{N})$. Additionally, $67 \%$ of responses were within 1 of this number (Figure 5). Mean responses at each capacity level corresponded quite closely to predictions (Table 3), with the exception of the treatment in which capacity is not constrained.

In Survey 2, respondents were told that their inclusion among a firm's suppliers resulted in added profit for that firm and had to determine how to divide this profit between themselves and the firm in order to remain a supplier in the future. The results are presented in Figure 6. While dispersion in the responses may mask the effect of capacity, regression analysis suggests a strong

\footnotetext{
${ }^{10}$ To minimize the effect of egocentric biases (Gorman and Kehr, 1992), half of the subjects in the first survey were asked about a fair profit for them if they were among the selected suppliers, and half were asked about a fair profit for other content providers. Subjects in the second survey were divided between questions about the appropriate percentage of profit to keep and to pay, to avoid bias in terms of losses or gains (Kahneman and Tversky, 1979).
} 


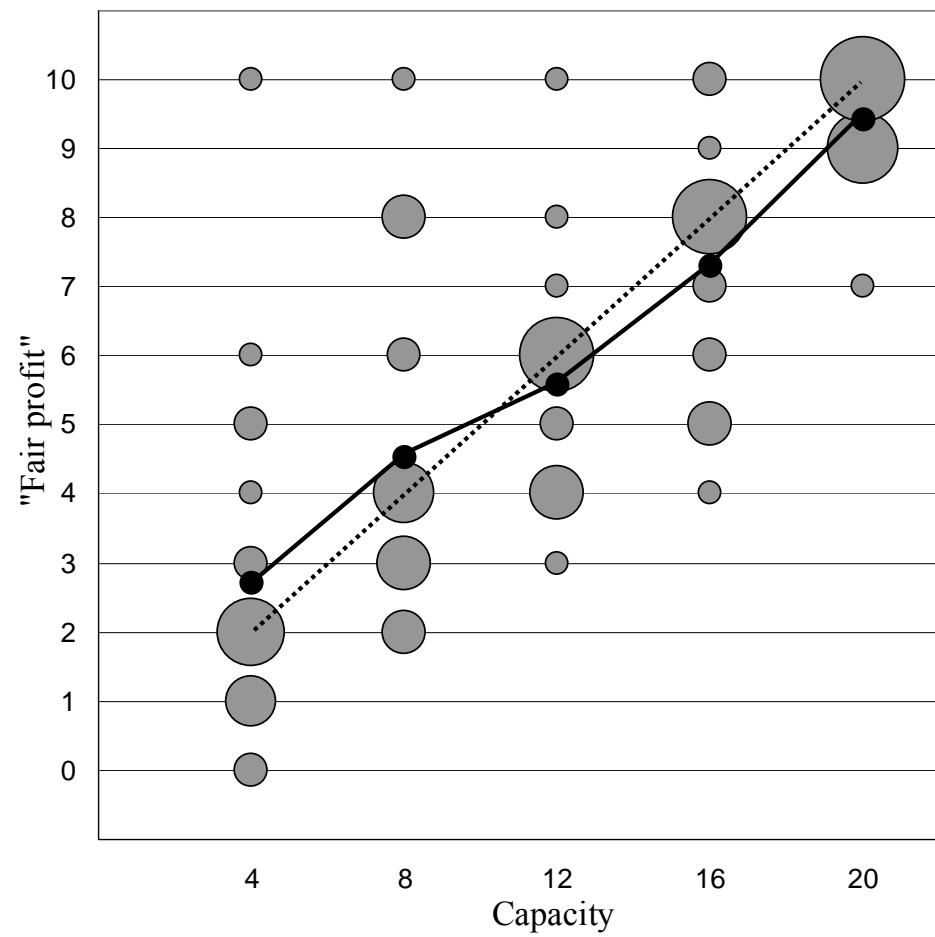

\section{............. Predicted "fair profit" \\ $\longrightarrow$ Average response \\ Responses}

Figure 5. Perceptions of "fair profit" at different capacity levels. Responses were rounded to the nearest integer for ease of presentation. Area of a circle is proportional to number of responses.

Table 3. Survey Results: Perceptions of Fair Profit

\begin{tabular}{c|ccc}
\hline \hline Capacity & Avg. Response (std. err.) & Hypothesized & p-value (obs = hyp) \\
\hline 4 & $2.70(.53)$ & 2 & 0.196 \\
8 & $4.53(.53)$ & 4 & 0.326 \\
12 & $5.58(.36)$ & 6 & 0.262 \\
16 & $7.29(.37)$ & 8 & 0.071 \\
20 & $9.42(.17)$ & 10 & 0.003 \\
\hline \hline
\end{tabular}

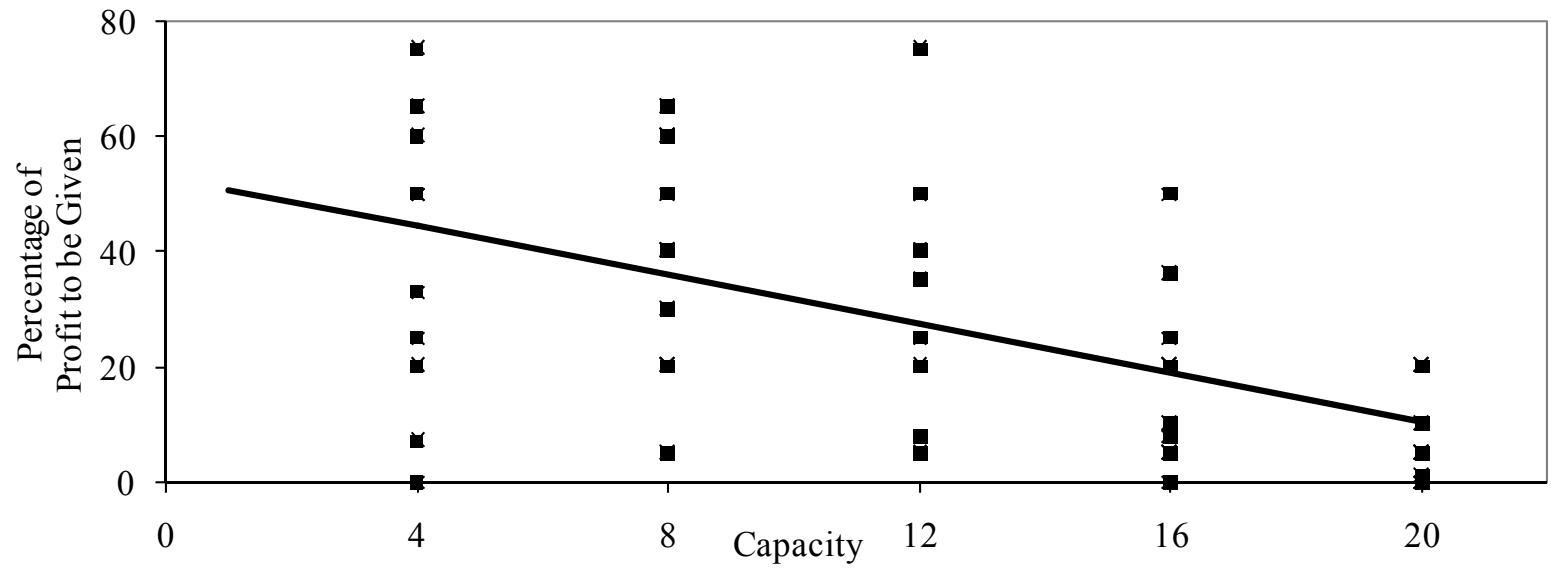

Figure 6. Percentage of supplier's added contribution that should be given to the firm according to survey respondents (regression line also shown). 
downward trend; the less binding is the capacity constraint, the less profit need be shared with the firm. Regressing responses on capacity level yields an intercept of 52.83 and a slope of -2.12, both highly significant $(\mathrm{p}<0.01)$. This would suggest that subjects believe, roughly, that at most half of the profit need be shared with the firm (when $k=1$ ) and when capacity constraints don't bind (at $k=20$ ), roughly $10 \%$ of a supplier's added contribution should be given to the firm.

Predictive power. The surveys may suggest if fairness or competitive concerns govern subjects' behavior. We can compute from the survey results what these respondents might have bid in the experimental game. For example, if fairness is the overriding concern, then responses to the first survey (a fair profit at varying capacity conditions) should resemble bids in the experiment. If competitive concerns govern behavior, then bids can be derived from the second survey; bids should resemble the value of each supplier multiplied by the proportion of profit to be kept by the supplier, according to survey responses. A third possibility also exists. Akin to the ultimatum games, it is possible that the equitable outcome serves as a focal point onto which subjects superimpose more strategic factors. A subject might begin by contemplating the "fair profit" (as per survey 1) but bid only some proportion of this (as per survey 2) given competitive concerns.

Figure 7 shows bids from the experiment as well as predicted bids using these three methods. Bids predicted from the fairness survey (panel a) appear do to well in reflecting the experimental data, though somewhat overestimate bids. Predictions based on survey 2 (panel b) significantly overstate actual bids, while the cumulative effect of both surveys, reducing the fairness norm of survey 1 by a percentage informed by survey 2 (panel c), resembles observed bids closely.

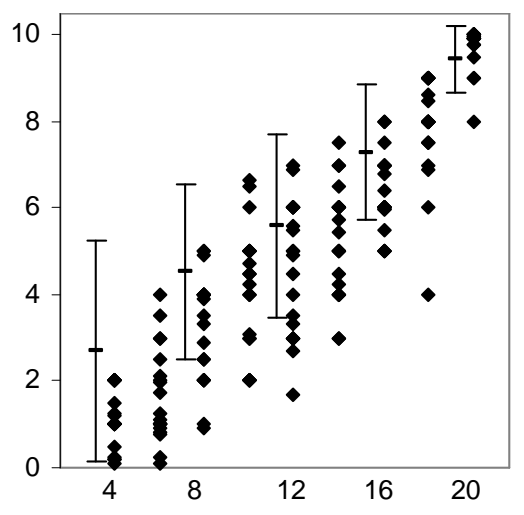

(a) fairness survey

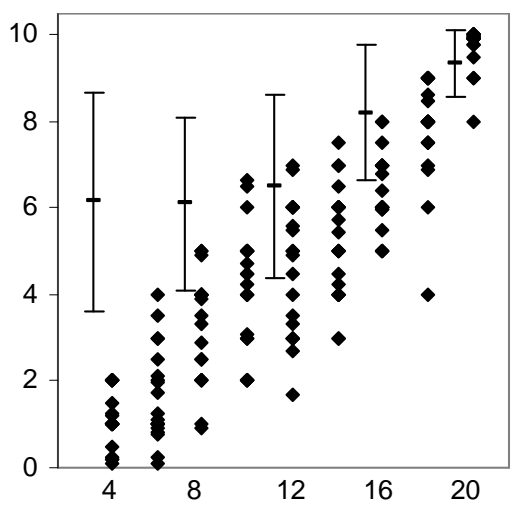

(b) competitiveness survey

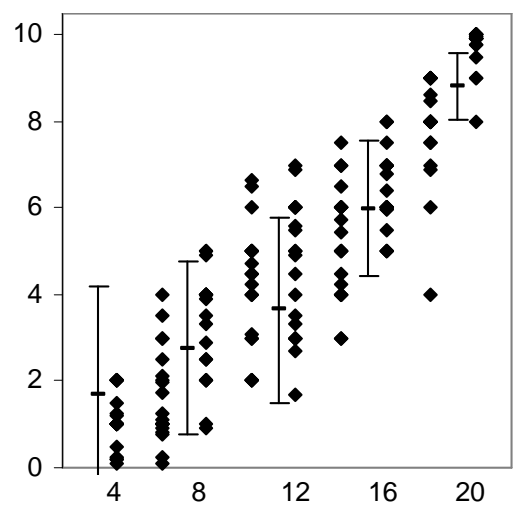

(c) both surveys

Figure 7. Observed bids (dots) and mean and standard deviation of predicted bids based on fairness survey, competitiveness survey, and cumulative effects of both surveys. 


\section{Repeated Encounters}

In many environments, bargaining is over long-term contracts and thus time does not allow for many repetitions of the encounter. The results above suggest that capacity can have a significant impact on the proposed profit shares of participants. A remaining question is whether these results survive learning in environments where more frequent interaction is possible. If the game is repeated, perhaps subjects' bids will show some convergence to equilibrium, as in Roth, Vesna, Okuno-Fujiwara, and Zamir (1991) or continue to exceed predictions, as in Dufwenberg, Gneezy, Goeree, and Nagel (2007) and some treatments of Dufwenberg and Gneezy (2000).

Three sessions were run in which twenty subjects would play the game at the same capacity condition, either $k=4,12$, or 18 , for twenty rounds. Twelve was chosen as it was the most profitable for the monopsonist in the one-shot experiment, and the others are the highest and lowest capacity-constrained conditions from the one-shot experiment. Each subject submitted in each round a price that she would receive if the offer was accepted. In each round, the $k$ lowest offers of the twenty submitted were accepted, with remaining subjects earning zero.

Subjects were informed after each round whether or not their offer was accepted, but not about other accepted or rejected offers. This differs from past experimental approaches, but reflects the practice of not disclosing terms of supplier contracts in most industries that motivate this study. ${ }^{11}$ Experimental dollars (up to 10 million per round) were converted into actual dollars at the rate of five million to one. Effectively, subjects could earn up to $\$ 2$ per round if the maximum possible offer was accepted. The average payment was $\$ 15.10$, in addition to a $\$ 5$ participation fee.

Figure 8 presents the accepted offers and Figure 9 presents the resulting profits for the monopsonist. No evidence of equilibrium convergence can be found in the $k=18$ or $k=12$ treatments, where bids remain significantly above zero in all twenty rounds. Instead, there appears to be a simple pattern in subject behavior. Perhaps not surprisingly, subjects ask for more when their previous offer was accepted and lower their request when their previous offer was rejected. Following an accepted bid, the next bid is strictly (weakly) higher 58\% (94\%) of

\footnotetext{
${ }^{11}$ For example, health maintenance organizations and pharmacy benefit managers, who oversee drug formularies for most private insurers, rarely disclose terms between drug companies and pharmacies and routinely lobby to defeat legislation calling for greater transparency (PCMA, 2006). Cable and satellite systems rarely disclose terms and some (e.g., Comcast) never do so. Neither Echostar nor Hearst-Argyle revealed terms of a recent agreement for the Lifetime network to be carried on the DISH system. A survey of grocers and their manufacturers found almost allo (93\%) do not believe that the terms of slotting allowances are known by competitors (Partch and De Santa, 1997).
} 


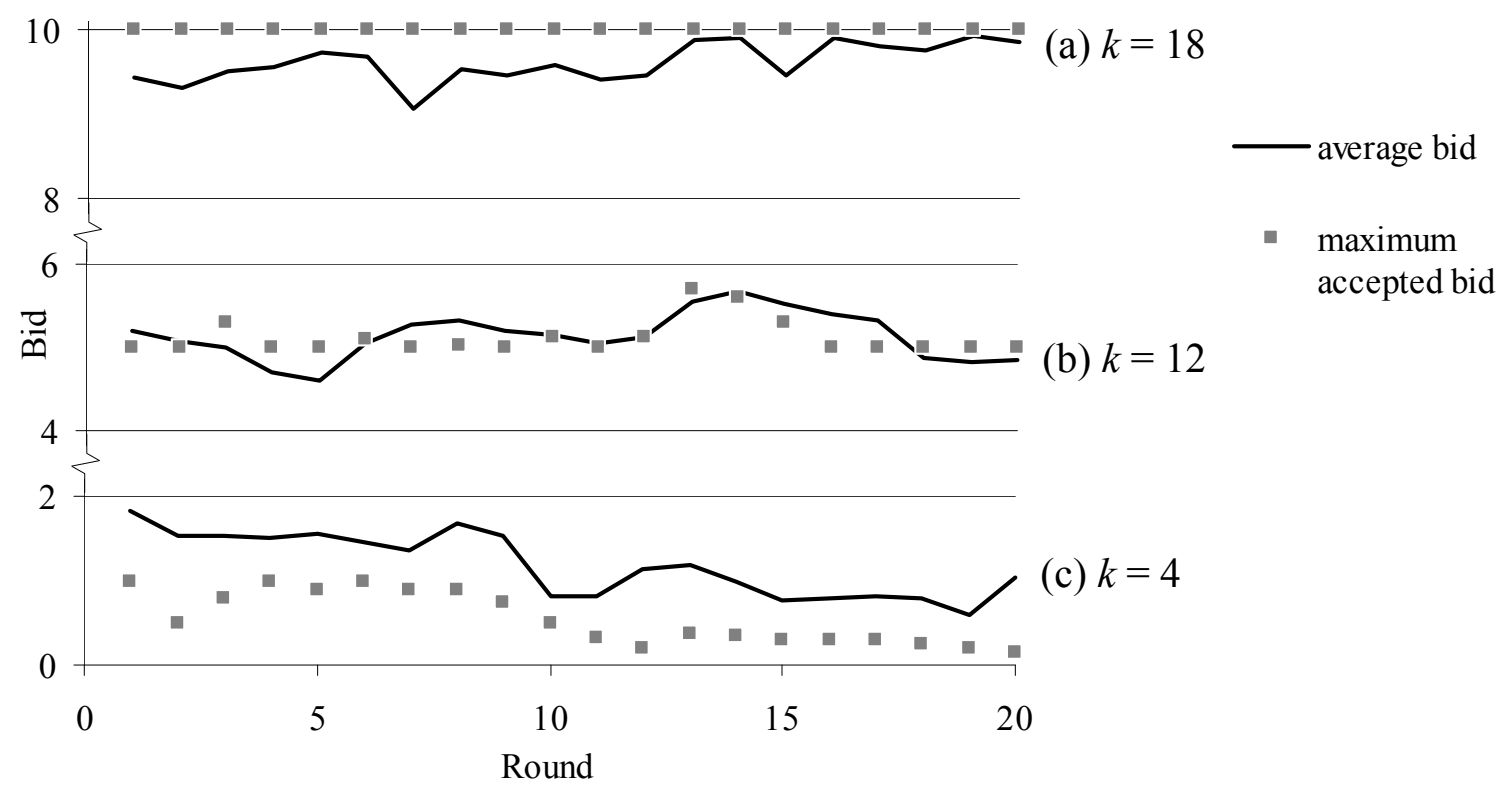

Figure 8. Average and maximum accepted bids in repeated play.

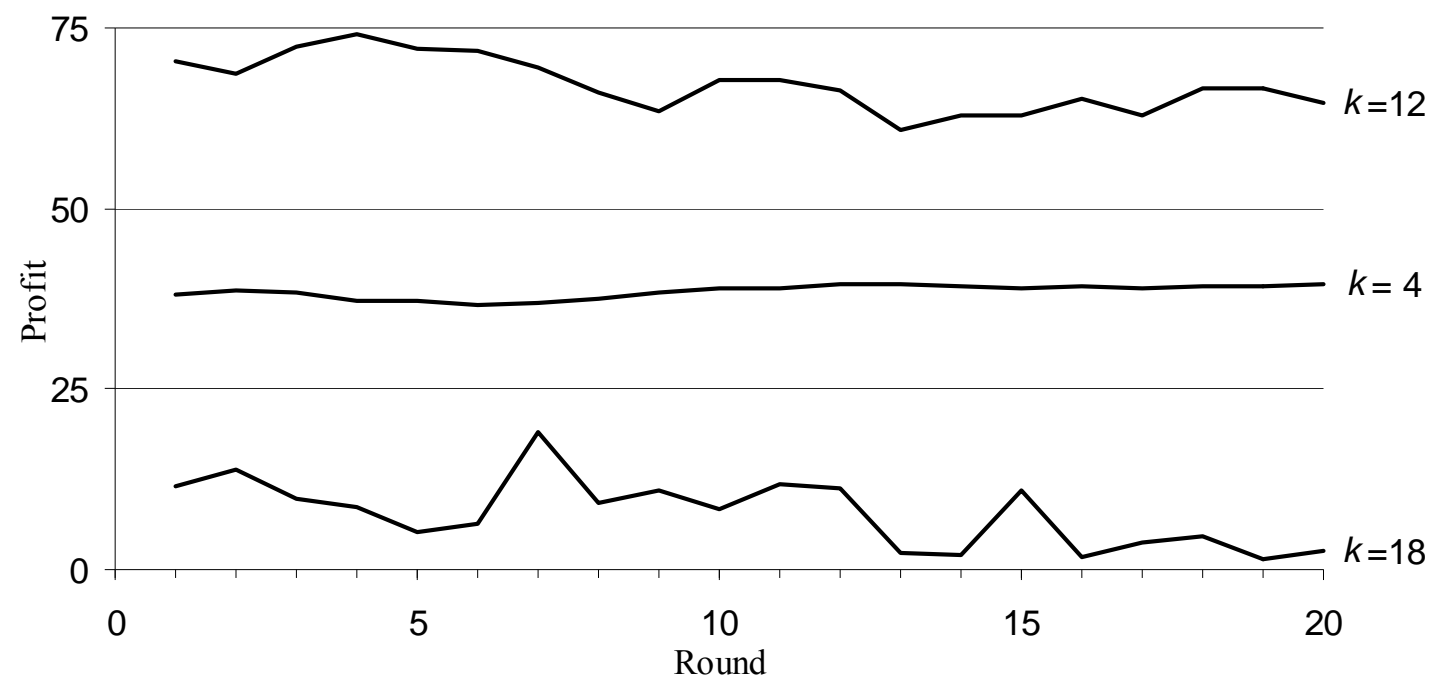

Figure 9. Firm profit. 
the time and following a rejected bid, the next bid is lower $74 \%$ (91\%) of the time. Additionally, the average adjustment downward following a rejected bid is $37 \%$ larger than the adjustment upward following an accepted bid. Since the number of subjects whose offers are accepted is given by $k$, almost every subject is increasing her bid each period when $k=18$ and most are reducing their bid each period when $k=4$, which can explain the trends in these treatments. When $k=12$, sixty percent of subjects' offers are accepted each period. This leads to more subjects increasing their bids each period than decreasing their bids, but bids decrease by more than they increase. These effects seem to offset, resulting in no clear trend in bids over time.

Since observations across rounds within the same session are not independent, both because the same subjects bid in each round, and because the behavior of one subject influences the behavior of others in future rounds, we effectively have only one data point for each of the three values of $k$. However, we can conclude that the incentives to reduce capacity significantly in order to gain greater bargaining power do not necessarily disappear in a repeated context. ${ }^{12}$

\section{Conclusion}

Subjects request a smaller share of the profit as capacity constraints become more stringent. The pattern of observed offers in the experiment appears to reflect both strategic and fairness concerns. A fairness benchmark is hypothesized and validated by surveys. Superimposing a second-order competitive effect on top of the fairness benchmark provides an accurate description of observed data. Subjects likely imagine their "fair share" of the profit but compromise on this value for strategic reasons. Alternate, more "rational" explanations, including Nash equilibrium and quantal response equilibrium, fail to explain observed data, and repeated play does not seem to nullify these results. The disequilibrium play by subjects provides an incentive for a firm to reduce its capacity to gain bargaining power over its suppliers.

In the proposed merger of satellite television broadcasters Echostar and DirecTV, the U.S. Department of Justice raised concerns that the merger would slow the growth of innovation. Without competitive pressures to provide better programming options, channel choice would grow slower than in the absence of merger. Satellite companies rebutted that they would

\footnotetext{
${ }^{12}$ Regressing bids on time, average bids on time, or autoregressing average bids on lagged bids and time all reveal the same trend: there is no significant change over time in the $k=12$ treatment, a slightly negative but significant trend for $k=4(\mathrm{p}<.01$ for regression, $\mathrm{p}=.03$ for AR), and slightly positive but significant trend for $k=18(\mathrm{p}<.01$ and $\mathrm{p}=.02$ ). On average, bids decline by $0.1 \%$ per round when $k=4$ and increase by $0.3 \%$ per round when $k=18$.
} 
immediately increase capacity as there would be no need for duplication of content. Since both companies currently carry HBO, for instance, they could instead devote the satellite capacity of one HBO slot to alternate programming. And why not? After all, this additional capacity would increase the value of the service to consumers which could then be appropriated in monthly fees.

The argument between satellite companies and regulators focused on the rate of future growth. What was not in doubt was that channel capacity would continue to increase. ${ }^{13}$ But cannot a monopoly have incentives to decrease capacity? In bargaining between satellite or cable companies and the programming distributors who provide them with content, often (as in the case of HBO or other movie channels) the channel's sole source of revenue is the payment from the satellite or cable company (Reiffen, Ward and Wiegand 2004). In a brief filed in support of the proposed DirecTV/EchoStar merger, it was argued that the single entity "would not face any disincentives to carry new programming that its subscribers would value" (Willig 2001, p. 27). These experiments call this view into question; the loss of bargaining power with respect to its suppliers provides one disincentive to increase capacity.

\footnotetext{
${ }^{13}$ See, for example, Willig (2001) and Rubinfeld (2002).
} 


\section{References}

Abbink, Klaus, Ron Darziv, Zohar Gilula, Harel Goren, Bernd Irlenbusch, Arnon Keren, Bettina Rockenbach, Abdolkarim Sadrieh, Reinhard Selten and Shmuel Zamir (2003). "The Fisherman's Problem: Exploring the tension between cooperative and non-cooperative concepts in a simple game." Journal of Economic Psychology 24(4): 425-445.

Arquit, Kevin J. (1991). “Antitrust Analysis of Slotting Allowances.” Remarks of the FTC Bureau of Competition Director before the National Grocers Association, November 12.

Bolton, Gary E., Elena Katok and Rami Zwick (1998). "Dictator game giving: Rules of fairness versus acts of kindness.” International Journal of Game Theory 27(2): 269-299.

Bulow, Jeremy, John Geanakoplos and Paul Klemperer (1985), "Holding idle capacity to deter entry." Economic Journal 95: 178-82.

Bykowsky, Mark, Anthony M. Kwasnica, and William Sharkey (2002). "Horizontal concentration in the cable television industry: an experimental analysis." FCC Office of Plans and Policy Working Paper No. 35.

Camerer, Colin and Richard H. Thaler (1995). "Anomalies: Ultimatums, dictators and manners." The Journal of Economic Perspectives 9(2): 209-219.

Dana, James (2004). “Buyer groups as strategic commitments.” Northwestern University working paper.

Deck, Cary A., and Bart J. Wilson (2007). “Experimental gasoline markets.” Journal of Economic Behavior and Organization, forthcoming.

Dufwenberg, Martin and Uri Gneezy (2000). "Price competition and market concentration: an experimental study.” International Journal of Industrial Organization 18(1): 7-22.

Dufwenberg, Martin, Uri Gneezy and Aldo Rustichini (2005). "Price competition: The role of gender and education" in S. Huck, ed., Advances in Understanding Strategic Behaviour: Game Theory, Experiments, and Bounded Rationality. Basingstoke: Palgrave Macmillan, 287-297.

Dufwenberg, Martin, Uri Gneezy, Jacob Goeree, and Rosemarie Nagel (2007). "Price floors and competition." Economic Theory 33(1), 211-224.

Fan, Terence P. and Amedeo R. Odoni (2002). "A practical perspective on airport demand management.” Air Traffic Control Quarterly 10(3): 285-306.

Fehr, Ernst and Klaus M. Schmidt (1999). "A theory of fairness, competition, and cooperation." Quarterly Journal of Economics 114(3): 817-868.

Forsythe, Robert, Joel L. Horowitz, N. E. Savin and Martin Sefton (1994). "Fairness in simple bargaining experiments.” Games and Economic Behavior 6(3): 347-369.

Froeb, Luke, and Mikhael Shor (2008), “An experimental test of multilateral bargaining power." Vanderbilt University working paper.

Gelman, Judith R. and Steven C. Salop (1983). "Judo economics: capacity limitations and coupon competition.” Bell Journal of Economics 14(2): 315-325. 
Goeree, Jacob, Charles Holt, and Thomas Palfrey (2005). "Regular quantal response equilibrium.” Journal of Experimental Economics 8(4): 347-367.

Gorman, Raymond F. and James B. Kehr (1992). "Fairness as a constraint on profit seeking: Comment." American Economic Review 82(1): 355-358.

Güth, Werner and Eric van Damme (1998). "Information, strategic behavior and fairness in ultimatum bargaining: An experimental study." Journal of Mathematical Psychology 42(2/3): 227-247.

Güth, Werner and Reinhard Tietz (1990). "Ultimatum bargaining behavior: A survey and comparison of experimental results." Journal of Economic Psychology 11(3): 417-449.

Haile, Philip A., Ali Hortacsu, and Grigory Kosenock (2007). "On the empirical content of quantal response equilibrium.” American Economic Review, forthcoming.

Huskamp, Haiden A., Richard G. Frank, Kimberly A. McGuigan, and Yuting Zhang (2005). "The impact of a three-tier formulary on demand response for prescription drugs." Journal of Economics \& Management Strategy 14(3): 729-753.

Kahneman, Daniel, Jack L. Knetsch and Richard H. Thaler (1986). "Fairness and the assumptions of economics.” Journal of Business 59(4): S285-S300.

Kahneman, Daniel and Amos Tversky (1979). "Prospect theory: An analysis of decision under risk." Econometrica 47(2): 263-291.

Klein, Benjamin, and Joshua D. Wright (2007). "The economics of slotting contracts." Journal of Law and Economics, forthcoming.

Marx, Leslie M. and Greg Shaffer (2004). "Slotting allowances and scarce shelf space.” Duke University working paper.

McKelvey, Richard D. and Thomas R. Palfrey (1995). "Quantal response equilibria for normal form games." Games and Economic Behavior, Elsevier, 10(1): 6-38.

Nagel, Rosemarie (2001). "Rationality and emotions in ultimatum bargaining: Comment." Annales D' Economie et De Statistique 61(1): 33-39.

Normann, Hans-Theo (2006). "Experimental economics for antitrust law and policy" in Collins, W., ed., Issues in Competition Law and Policy. American Bar Association, forthcoming.

Normann, Hans-Theo, Bradley J. Ruffle, and Christopher M. Snyder (2007). "Do buyer-size discounts depend on the curvature of the surplus function? Experimental tests of bargaining models." RAND Journal of Economics, forthcoming.

O’Brien, Daniel P. and Greg Shaffer (1997). "Nonlinear supply contracts, exclusive dealing, and equilibrium market foreclosure." Journal of Economics and Management Strategy 6(4): $755-785$.

Ochs, Jack and Alvin E. Roth (1989). "An experimental study of sequential bargaining." American Economic Review 79(3): 355-384.

Partch, Ken and Richard De Santa (1997). "Slotting: the issue that won't go away." Supermarket Business 52(5): 12-19.

PCMA (2006). "New York, Rhode Island, and Delaware all reject PBM fiduciary-disclosure proposals.” Press Release, Pharmaceutical Care Management Association, 11 July 2006. 
Pitofsky, Robert (2000). Testimony before the Subcommittee on Antitrust, Business Rights, and Competition, U.S. Senate, March 22.

Prasnikar, Vesna and Alvin E. Roth (1992). "Considerations of fairness and strategy: experimental data from sequential games.” Quarterly Journal of Economics 107(3): 865888.

Roth, Alvin E. (1995) "Bargaining experiments" in J. H. Kagel and A. E. Roth, eds., The Handbook of Experimental Economics. Princeton: Princeton University Press, 253-348.

Roth, Alvin E., Vesna Prasnikar, Masahiro Okuno-Fujiwara and Shmuel Zamir (1991). "Bargaining and market behavior in Jerusalem, Ljubljana, Pittsburgh, and Tokyo: An experimental study." American Economic Review 81(5): 1068-1095.

Rubinfeld, Daniel (2002). "Affidavit and report of Dr. Daniel L. Rubinfeld," Attachment A to Pegasus Communications Corporation's Petition to Deny, FCC Filing, docket 01-348.

Schotter, Andrew (2002). "Declaration on behalf of AT\&T Corp." Federal Communications Commission, 18 July 2002.

Selten, Reinhard and Axel Ockenfels (1998). "An experimental solidarity game." Journal of Economic Behavior and Organization 34(4): 517-539.

Shor, Mikhael (2007). "Rethinking the fairness hypothesis: procedural justice in simple bargaining games." Vanderbilt University working paper.

Spence, A. Michael (1977). "Entry, capacity, investment and oligopolistic pricing." Bell Journal of Economics 8(2): 534-544.

Sullivan, Mary W. (1997). "Slotting allowances and the market for new products." Journal of Law and Economics 40(2): 461-493.

Thaler, Richard H. (1988). "Anomalies: The ultimatum game.” The Journal of Economic Perspectives 2(4): 195-206.

Tom, Willard K. (1999). "Slotting Allowances and the Antitrust Laws." Testimony before the Committee on Judiciary, U.S. House of Representatives, October 20.

von Ungern-Sternberg, Thomas (1988). "Excess capacity as a commitment to promote entry." Journal of Industrial Economics 37(2): 113-122.

Weg, Eythan and Rami Zwick (1994). "Toward the settlement of the fairness issues in ultimatum games: A bargaining approach." Journal of Economic Behavior and Organization 24(1): 19-34.

Walster, Elaine, G. William Walster and Ellen Berscheid (1978). Equity: Theory and research. Boston: Allyn and Bacon.

Willig, Robert (2001). "Declaration of Robert Willig on behalf of Echostar Communications Corporation, General Motors Corporation and Hughes Electronics Corporation," Consolidated Application for Authority to Transfer Control (Attachment A), Volume I, FCC Filing, docket 01-348.

Zamir, Shmuel (2001). 'Rationality and emotions in ultimatum bargaining." Annales D' Economie et De Statistique 61(1): 1-31. 


\section{Appendix A. Experiment Instrument}

You are the executive director for a commercial-free music video content provider - a cable channel featuring twenty-four hours a day of music videos without commercial interruption. Various cable systems must decide whether to carry your channel or those of your competitors, of which there are nineteen (or twenty commercial-free music channels in total, including yours). Also, various cable systems differ in their capacity, and thus in their ability to carry multiple music channels. For example, some small towns have older cable networks which can carry very few channels, and thus may have room for only a single music video provider. Larger systems in metropolitan areas may have room for as many as twenty channels just for music videos, and thus can carry every commercialfree music channel that exists.

Since your channel and others like it do not receive revenue from advertisements or commercials, cable companies pay a one-time fee to the content providers for the right to carry their channel. Every additional music video channel carried by a cable company results in $\$ 10$ million dollars in profits for the cable company (in net present value terms). For you, there is no additional cost from being carried by other cable providers, nor any additional profit except for the payment made by the cable company to you.

Each cable company selects the channels that it will carry through an auction:

- First, each cable company announces the number of channels that it will allocate to music video content.

- Second, each music video content provider submits a bid - which is how much the provider must receive from the cable company for the right to provide its channel.

- Third, the cable company selects the best bids of the twenty submitted, based on its capacity, and pays each of those firms its asking rate, or bid, as long as that bid does not exceed $\$ 10$ million.

Consider an example (all numbers are selected randomly). One cable company announces that it has room for six channels devoted to commercial free music video content. You submit a bid of $\$ 2.5$ million, meaning that you will allow the cable company to air your channel for a one-time payment of $\$ 2.5$ million. The other 19 firms (other experiment participants) submit bids of (in millions):

$\$ 1, \$ 1.2, \$ 2, \$ 2, \$ 3, \$ 4, \$ 4, \$ 4, \$ 5.5, \$ 6, \$ 6, \$ 7, \$ 7, \$ 7, \$ 8, \$ 9, \$ 9, \$ 9.9, \$ 10$.

The cable company selects the six best bids, which are (in millions)

$\$ 1, \$ 1.2, \$ 2, \$ 2, \$ 2.5$ (yours), and \$3.

These content providers receive their asking price (your firm receives $\$ 2.5$ million) and the remaining 14 firms receive $\$ 0$.

Your firm has asked you to place a bid in three such auctions in three different markets. They will compensate you for any success at the rate of $\$ 1$ for you for every $\$ 1$ million for the firm. For example, if in one of the auctions, you bid (ask for a payment of) $\$ 5$ million and the cable company accepts, your firm will compensate you $\$ 5$, payable in cash at the conclusion of the experiment.

Each market has a different capacity - that is, the three cable companies have reserved different amounts of channels for commercial-free music video content. The capacity indicates how many of the best (lowest) bids the cable company will accept. For each of the three markets, denote your bid in millions of dollars. That is, a bid of $\$ 2$ indicates two million dollars, and a bid of $\$ 7.5$ indicates $\$ 7,500,000$.

\section{Market 1}

\section{The capacity in this market is 12}

The cable company will accept the 12 lowest bids of the twenty it receives as long as they are at below $\$ 10 \mathrm{M}$.

How much will you bid, in millions of dollars? In other words, how much are you willing to accept for the cable company to offer your channel content?

$$
\text { Bid: } \$ \text { million }
$$

[Note: Each subject participates in three markets at different capacity levels] 


\section{Appendix B. Survey Instruments}

\section{Survey 1: Fair profit}

A television cable system has decided to devote several channels to commercial-free music video, channels featuring twenty-four hours a day of music videos. Cable companies often do not produce these channels themselves but instead license them from content providers. Since the content is without commercial interruption, these providers do not receive revenue from advertisements or commercials. Instead, the cable company pays a one-time fee for the right to carry their channel.

Consider one specific case. A particular cable system has found that every music video channel that it carries results in an additional \$10 million dollars in profits for the cable company. The content providers have no extra cost of being carried by the cable company (since the content has to be produced anyway) and receive no additional profit except for the payment made by the cable company to them. A total of twenty content providers exist but the cable company has room for only [twelve] channels to devote to music videos. Thus, out of the twenty providers, [twelve] will be carried by the cable company and [eight] will not.

In summary, the cable company will select [twelve] of the twenty content providers. Thus, out of the twenty content providers, [twelve] will be able to offer their channel content. Each of these [twelve] channels carries a value of $\$ 10$ million dollars for the cable company.

Question Format 1 (you):

If you are the executive director of one of the [twelve] selected content providers, what level of profit is a fair profit for you to receive?

Question Format 2 (other):

What level of profit is a fair profit for each of these [twelve] content providers to receive?

\section{Survey 2: Competitive effects}

Your company is a television content provider producing a channel of interest to a specific market segment. A television cable system has decided to devote space to your channel. A total of twenty content providers (including you) exist in your market segment but the cable company has room for only [twelve] channels to devote to this segment. Thus, out of the twenty providers, [twelve] are carried by the cable company and [eight] are not.

From your inclusion by this cable company, you earn a profit. Since the cable company cannot carry every available channel and decisions as to channel lineup are reconsidered periodically, your company is contemplating sharing some of its profits with the cable company.

Question Format 1 (you):

If you are the executive director of one of the [twelve] selected content providers, what percentage of your profit do you think you can keep without jeopardizing your position in the cable company's channel lineup?

Question Format 2 (other):

If you are the executive director of one of the [twelve] selected content providers, what percentage of your profit do you think you should share with the cable company to not jeopardize your position in their channel lineup? 